\title{
Commentary: "Proceed to and follow the highlighted route"-Thoracic surgical Waze is here
}

\author{
Moishe Liberman, $\mathrm{MD}, \mathrm{PhD}$
}

\footnotetext{
From the Division of Thoracic Surgery, University of Montréal, Montréal, Québec, Canada; and CHUM Endoscopic Tracheo-bronchial and Oesophageal Center (CETOC), Montréal, Québec, Canada.

Disclosures: Author has nothing to disclose with regard to commercial support.

Received for publication Jan 1, 2019; accepted for publication Jan 1, 2019; available ahead of print Feb 15, 2019. Address for reprints: Moishe Liberman, MD, PhD, Division of Thoracic Surgery, C.E.T.O.C., Centre Hospitalier de l'Université de Montréal Centre de Recherche du CHUM, Room R04.402-1 900 Rue Saint-Denis, Montreal, Quebec H2X 0A9, Canada (E-mail: moishe.liberman@umontreal.ca).

J Thorac Cardiovasc Surg 2019;157:2036-7

$0022-5223 / \$ 36.00$

Copyright (c) 2019 by The American Association for Thoracic Surgery

https://doi.org/10.1016/j.jtcvs.2019.01.005
}

In this edition of the Journal, Mehta and colleagues ${ }^{1}$ report on a prospective cohort study evaluating near-infrared fluorescence mapping with indocyanine green (ICG) dye for evaluating intersegmental planes, with the goal of increasing oncologic margins in robotic anatomic segmentectomy. The technique has been well described ${ }^{2-4}$ and is not technically cumbersome. It involves ligating the segmental bronchus, artery, and vein and then infusing ICG dye intravenously. The isolated segment will not receive dye, and a near-infrared fluorescence light source that detects ICG is used to identify the anatomic boundaries of the segment that does not uptake ICG. Data such as those described in this study are extremely important before widespread incorporation of ICG evaluation into clinical practice.

This single-surgeon trial is both interesting and important in defining the efficacy and feasibility of ICG evaluation with near-infrared fluorescence in vivo in a large group of prospectively assessed patients. The high percentage of patients who granted consent but did not undergo planned segmentectomy $(22 / 53 ; 41.5 \%)$ is unusual and is likely related to the inexperience of the center in robotic anatomic segmentectomy, as stated in the article's discussion. ${ }^{1}$ This fact probably signifies that the results underestimate the actual value of ICG intersegmental fissure assessment, because it is quite rare to convert a segmentectomy to a lobectomy in high-volume centers with experience in the technique and patient selection with preoperative computed tomographic scan evaluation. Reproducibility is difficult to assess because of the single-surgeon experience in this study.

The technique used in this study should result in similar outcomes in patients undergoing video-assisted thoracoscopic surgery or open segmental resection, because there is nothing particular to this technique that requires a robot. 5 This is important when evaluating costeffectiveness of new technology. The fact that ICG with near-infrared fluorescence assessment of anatomic intersegmental planes can be performed without requiring the robot

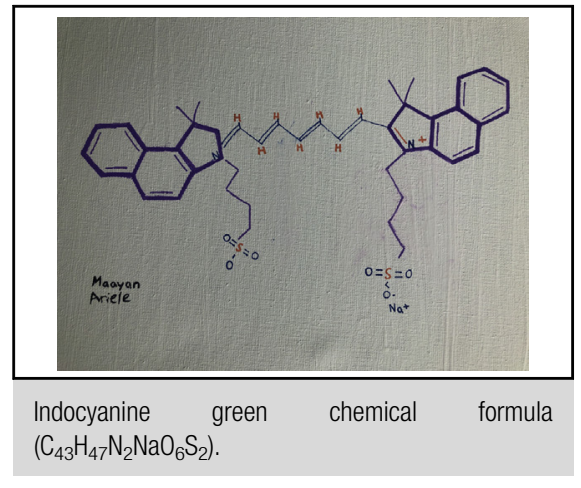

Central Message

Near-infrared fluorescence mapping with indocyanine green dye has the potential to guide surgeons to the correct intersegmental plane and thus allow increased surgical margins during anatomic segmentectomy.

See Article page 2029.

should make the cost evaluation for new technology acquisition easier in hospitals that either do not have a robot or limit robot use to cases in which there is a true added value associated with the increased cost per procedure.

The future of the technical components of thoracic surgery will be awe-inspiring. With real-time image-guided procedures, GPS navigational planning, anatomic preoperative and intraoperative planning, and augmented artificial intelligence, thoracic surgeons will be able to provide the most precise, healthy tissue-preserving and minimally invasive resections ever for our patients. Studies such as this one are extremely important to allow evidence-based evaluation of new technology. Large-scale, multicenter trials are necessary to assess generalizability, reproducibility, efficacy, and cost.

We are getting closer to the point of being guided by technology in all aspects of the technical phases of surgical procedures. We are already accustomed to our phones or cars telling us where to go; it will not be long before intraoperative imaging modalities will tell us to "proceed to and follow the highlighted route." Thoracic surgical Waze is here.

\section{References}

1. Mehta M, Patel Y, Yasufuku K, Waddell TK, Shargall Y, Fahim C, et al. Nearinfrared mapping with indocyanine green is associated with an increase in 
oncological margin length in minimally invasive segmentectomy. J Thorac Cardiovasc Surg. 2019;157:2029-35.

2. Misaki N, Chang SS, Igai H, Tarumi S, Gotoh M, Yokomise H. New clinically applicable method for visualizing adjacent lung segments using an infrared thoracoscopy system. J Thorac Cardiovasc Surg. 2010;140:752-6.

3. Pardolesi A, Veronesi G, Solli P, Spaggiari L. Use of indocyanine green to facilitate intersegmental plane identification during robotic anatomic segmentectomy. $J$ Thorac Cardiovasc Surg. 2014;148:737-8.
4. Keating J, Singhal S. Novel methods of intraoperative localization and margin assessment of pulmonary nodules. Semin Thorac Cardiovasc Surg. 2016;28:127-36.

5. Mun M, Okumura S, Nakao M, Matsuura Y, Nakagawa K. Indocyanine green fluorescence-navigated thoracoscopic anatomical segmentectomy. J Vis Surg. 2017;3:80.

6. Tarumi S, Masaki N, Kasai N, Chang SS, Go T, Yokomise H. Clinical trial of video-assisted thoracoscopic segmentectomy using infrared thoracoscopy with indocyanine green. Eur J Cardiothorac Surg. 2014;46:112-5. 